\title{
Oral Cancer Knowledge Assessment: Newly Graduated versus Senior Dental Clinicians
}

\author{
Gisele Pavão Spaulonci (D), Ricardo Salgado de Souza, Vanessa Gallego Arias Pecorari, and \\ Luciano Lauria Dib
}

Paulista University (UNIP), Indianópolis, SP, Brazil

Correspondence should be addressed to Gisele Pavão Spaulonci; giselepavao@terra.com.br

Received 11 September 2017; Accepted 27 December 2017; Published 14 February 2018

Academic Editor: Silvio Abati

Copyright (C) 2018 Gisele Pavão Spaulonci et al. This is an open access article distributed under the Creative Commons Attribution License, which permits unrestricted use, distribution, and reproduction in any medium, provided the original work is properly cited.

\begin{abstract}
The present study assessed the level of dentists' knowledge regarding oral cancer in the city of São Paulo, Brazil. A questionnaire was used to compare the level of knowledge among newly graduated and senior clinicians. A total of 20,154 e-mails were correctly delivered to the dentists registered in the database of the Regional Dentistry Council of São Paulo, and 477 (2.36\%) responses were received. This sample consisted of 84 newly graduated clinicians and 105 senior clinicians. For the statistical analysis, the chisquare test and the logistic regression analysis were performed with $\alpha=0.05$, and the results were described herein. According to their knowledge level, the results were statistically different between the groups, since $19 \%$ of the newly graduated clinicians were evaluated with knowledge grade A (excellent) in comparison to $6.7 \%$ of the senior clinicians. In spite of the results indicated that newly graduated clinicians' knowledge regarding oral cancer was 2.1 times higher, $34.5 \%$ of the professionals in this group had regular or poor knowledge on the subject, and several questions relating to clinical characteristics and risk factors indicated that there still exist some knowledge gaps, demonstrating that there is a need for further studies and information activities addressing oral cancer.
\end{abstract}

\section{Introduction}

Oral cancer is considered a worldwide public health problem. It is the sixth most frequent type of cancer, and two out of three cases occur in developing countries $[1,2]$. The Brazilian National Cancer Institute (INCA) had estimated the occurrence of 11,140 new cases of oral cancer in men and 4,350 in women in 2016 [3]. According to this estimation, the south and southeast regions would be the most affected, with the highest incidence rates [3].

The most prevalent type of cancer is the squamous cell carcinoma [3-5]. It is considered to have poor prognosis [6], with a five-year survival rate in 50 to $60 \%$ of cases $[1,6,7]$. It is worth mentioning that there has not been notable prognosis improvement in the recent decades [5-7].

The patients' survival rate and the functional consequences are related to the disease staging at the time of diagnosis [8]. The early detection and the immediate treatment of oral cancer may reduce the mortality rates $[1,2,5,9-11]$. However, studies have demonstrated that two out of three cancers are diagnosed in advanced stages (III and IV) [2, $10,12-14]$. This delay in diagnosis is due to factors related to patients [13-15], health profissionais [13, 14], and the health system, as the late diagnosis has also been associated with the difficult access to specialized services, especially for people who live away from large centers [15].

The shortage of dental professionals and dental schools in Brazil may be ruled out as a possible factor for this delay [16], given that there are currently more than 280,000 professionals and 220 dental schools in the country [17].

The oral cancer may be identified at an early stage by means of visual and tactile examinations, and the dentists are key role health professionals in counselling patients about early detection of this disease [18]. The preventive role of these professionals relies on the fact that they have the greatest chances to identify asymptomatic lesions through 
routine examinations and to diagnose the disease before it starts unfolding, revealing its devastating consequences [19]. This fact emphasizes the importance of assessing the clinical professional knowledge regarding oral cancer risk factors and its diagnostic procedures.

Studies have been carried out in several parts of the world, indicating dentists' poor or lacking knowledge regarding oral cancer [2, 14, 18, 20-25]. In Brazil, some studies have been performed using a questionnaire previously published in the study of Dib et al. [19], which, at that time, demonstrated the low level of professional knowledge on this theme [8, 26-29].

Previous studies in countries like Yemen and Canada have suggested that newly graduated professionals had more knowledge in comparison to senior professionals [4, 25]. The hypothesis of the present study is that there may be differences in dentists' knowledge due to the number of years of professional experience or seniority. However, there are doubts whether newly graduated dentists have more knowledge than seniors for being closer to their university experience period or whether the most experienced professionals know more for having more clinical practice years. In addition, it should be taken into consideration that professionals with 30 years of experience or more have received information from the studies carried out in the 1980s, which have indicated cancer aspects that are similar to those found in current studies [30-32].

In Brazil, there are no studies that have assessed these differences justified by the time of experience with regard to oral cancer knowledge. Therefore, the objective of the present study was to assess dentists' knowledge about oral cancer by means of a literature-validated questionnaire (Figure 1) and to compare the knowledge level among two groups of professionals: junior or newly graduated (0 to 5 years of professional practice) versus senior dental clinicians (above 30 years of experience).

\section{Materials and Methods}

The present study was approved by the Research Ethics Committee of Paulista University (UNIP), São Paulo, Brazil (approval report 1,543,946-CAAE 54493716.8.0000.5512).

A cross-sectional observational study was carried out, where the database of the Regional Dentistry Council of São Paulo was accessed, which contained 28,671 listed professionals at the time of questionnaire submission, out of which 25,321 had their e-mails listed in their profile within the council database.

A questionnaire validated by Dib et al. [19] was modified and uploaded for online accessing using the Survey Monkey online platform (Survey Monkey Brazil Internet Ltd., São Paulo, Brazil) (Figure 1). The e-mails with the invitation to participate in the study along with the web link to access the questionnaire and a published consent form were distributed on July 2016 to the 25,321 listed dentists.

Out of all e-mails sent, 5,167 were not received due to outdated profile information or incorrect e-mail addresses in the profiles, and 20,154 e-mails were correctly received. After allowing one month for responses, the received data were fed into an Excel spreadsheet. The participation was anonymous, and no personal identification from the participants was registered.

The questionnaire consisted of 39 items divided into three parts (Figure 1). The first part covered the participants' general characteristics regarding their clinical practice related to the disease and interest in the topic. Values were not attributed to the responses in the first part. The second part addressed the knowledge about the clinical characteristics of oral cancer occurrence through six questions. Each question was worth one point. The third part consisted of 17 questions regarding risk factors, along with the question about oral cancer identification and diagnosis stage and time, totalling four points (Figure 1).

Grades were attributed to each participant according to their knowledge level. The applied criteria were A (excellent) for those who scored from 9 to 10 points; B (good) for those who scored from 7 to 8.99 points; $\mathrm{C}$ (regular) for those who scored from 5 to 6.99 points; and D (poor) for those who scored below 4.99 points.

The variables "age" and "seniority" (Figure 1) were categorized to perform the cross-tabulation of the questions and compared according to the junior and senior dental clinicians' knowledge level.

The statistical analysis was carried out in two stages. First, the univariate test was performed using Pearson's chisquare test with $\alpha=0.20$ to detect possible associations of the responses according to the time of formation. Subsequently, a multiple logistic regression analysis was performed with $\alpha=0.05$, with the dependent variable being the appropriate level of knowledge (A and B) in function of the independent variables (age, gender, time of experience, graduation institution, self-assessment of knowledge, level of confidence in performing diagnostic procedures, training at the university, qualification, and if attended a course on oral cancer) to obtain the odds ratios and the confidence intervals. The SPSS 22 statistical program was used (Statistical Package for Social Sciences, IBM ${ }^{\mathrm{TM}}$, Chicago, USA).

\section{Results}

A total of 20,154 e-mails were sent; however, only 477 of them were replied, representing a response rate of $2.36 \%$. The participants were grouped according to practice seniority in order to compare 84 newly graduated dental clinicians with 105 senior dental clinicians. With this, the sample corresponded to 189 participants (Tables 1-6).

There was a statistical difference in the variable "gender" according to seniority in the comparison between the two groups (Table 1). The percentage of junior female dental clinicians was $78.6 \%$, whereas the percentage of senior female dental clinicians was $57.1 \%$ (Table 1 ).

Regarding the knowledge level, there was a statistical difference according to the participants' seniority. Among the newly graduated dental clinicians, $19 \%$ obtained grade A (excellent), whereas only $6.7 \%$ of the senior dental clinicians obtained the same grade (Table 1).

The assessment of the variable "qualification" (Figure 1) showed that the results were also statistically different according to seniority (Table 1). Among the junior dental clinicians, 55.9\% reported being general dental practitioners, 
* 1. Age:

( )

* 2. Gender:

( ) Male

( ) Female

*3. Time of experience:

( )

* 4. Undergraduation institution:
( ) Public

( ) Private

* 5. What is your highest qualification (general practitioner, specialist, Master's degree, Ph.D.) and in which area?

*6. What is your self-assessment of your level of oral cancer knowledge?
( ) Excellent
( ) Good
( ) Fair
( ) Poor

* 7. Do you perform a dental examination to detect oral cancer in the first appointment of your patients?

( ) Yes

( ) No

* 8. Explain why you do not perform oral cancer examination.
( ) I perform the examination
( ) I do not know how to do it
( ) I do not think it is necessary
( ) I do not receive payment for the examination

* 9. When you detect malignancy suspected lesions, how do you refer the cases?
( ) I perform the diagnostic procedures
( ) Dental surgeons specialized in stomatology
( ) Physicians
( ) Dental schools
( ) Specialized hospitals
( ) When it is not the main patients' complaint, I wait until they ask for guidance

* 10. Which is the most common type of oral cancer?
( ) Lymphoma
( ) Squamous cell carcinoma
( ) Kaposi's sarcoma
( ) Ameloblastoma
( ) Adenoma of salivary glands
( ) I do not know

* 11. Which is the most frequent anatomical region for oral cancer?
( ) Tongue
( ) Oral floor
( ) Gingiva
( ) Palate
( ) Jugal mucosa
( ) I do not know

* 12. Among the mentioned issues, which is the most common aspect in patients with initial oral cancer?
( ) Abundant salivation
( ) Painless ulcer
( ) Hard nodule
( ) Intense pain
( ) I do not know

FIgURe 1: Continued. 
* 13. Which is the predominant age group with oral cancer occurrence?
( ) Less than 18 years
( ) 18 to 39 years
( ) More than 40 years
( ) I do not know

* 14. When the most characteristic cervical lymph node metastases in oral cancer are palpated, they are:

( ) Hard, painful, with mobility

( ) Hard, painless, with or without mobility

( ) Soft, painful, with mobility

( ) Soft, painless, with or without mobility

( ) I do not know

* 15. According to epidemiological data, which oral cancer stage is most frequently diagnosed in Brazil?

( ) Pre-malignant

( ) Early

( ) Advanced

( ) I do not know

* 16. Which of the following conditions is more commonly associated to oral cancer?
( ) Leukoplakia
( ) Pemphigus vulgaris
( ) Stomatitis
( ) Candidiasis
( ) Geographic tongue
( ) I do not know

In questions 17 to 33 answer whether or not you consider the condition mentioned as a risk factor for oral cancer

* 17. Use of injectable drugs:
( ) Yes
( ) No

* 18. Having previously had other types of cancer:
( ) Yes
( ) No

* 19. Consumption of alcohol:
( ) Yes
( ) No

*20. Use of tobacco:
( ) Yes
( ) No

* 21. Family history of cancer:
( ) Yes
( ) No

* 22. Emotional stress:
( ) Yes
( ) No

* 23. Lower consumption of fruit and vegetables:
( ) Yes
( ) No

* 24. Oral sex:

( ) Yes

( ) No

* 25. Poorly fitting dentures
( ) Yes
( ) No 
* 26. Poor dental status:
( ) Yes
( ) No

* 27. Consumption of spicy food:
( ) Yes
( ) No

* 28. Poor oral hygiene:
( ) Yes
( ) No

* 29. Direct infection:
( ) Yes
( ) No

* 30. Sun exposure:
( ) Yes
( ) No

* 31. Hot beverages and food:
( ) Yes
( ) No

* 32. Obesity:

( ) Yes

( ) No

* 33. HPV infection:

( ) Yes

( ) No

* 34. Do you consider your patients sufficiently informed about oral cancer (prevention and diagnosis)?

( ) Yes

( ) No

( ) I do not know

* 35. What is your level of confidence in performing diagnostic procedures to detect oral cancer?
( ) High
( ) Low
( ) I do not know

* 36. Do you consider that the university provided training on oral cancer examination during your undergraduate program?
( ) Yes
( ) No
( ) I do not know

* 37. When was the last time you attended a continuing education course on oral cancer?
( ) Last year
( ) During the last two years.
( ) More than two years.
() Never
( ) I do not remember.

* 38. Are you interested in attending a continuing education course on oral cancer in the future?
( ) Yes
( ) No
( ) I am not sure.

*39. According to your opinion, what is the level of importance of the dental surgeon in the prevention and early diagnosis of oral cancer?
( ) High
( ) Medium
( ) Fair
( ) Low
( ) I do not know

Figure 1: Questionnaire applied to assess oral cancer knowledge (Survey Monkey Brazil Internet Ltd.). 
TABle 1: Distribution of the number and percentages of responses regarding dentists' general characteristics according to responders' seniority.

\begin{tabular}{|c|c|c|c|c|c|}
\hline \multirow{2}{*}{ Categorical } & \multirow{2}{*}{ Variables } & \multicolumn{2}{|c|}{ Dental clinicians } & \multirow{2}{*}{ Total (\%) } & \multirow[b]{2}{*}{$p$} \\
\hline & & Junior & Senior & & \\
\hline \multirow[t]{4}{*}{ Grade obtained } & A (excellent) & $16(19 \%)$ & $7(6.7 \%)$ & $23(12.2 \%)$ & $0.025^{*}$ \\
\hline & B (good) & $39(46.4 \%)$ & $44(41.9 \%)$ & $83(43.9 \%)$ & \\
\hline & $\mathrm{C}$ (regular) & $20(23.8 \%)$ & $40(38.1 \%)$ & $60(31.7 \%)$ & \\
\hline & $\mathrm{D}$ (poor) & $9(10.7 \%)$ & $14(13.3 \%)$ & $23(12.2 \%)$ & \\
\hline \multirow[t]{2}{*}{ Gender } & Female & $66(78.6 \%)$ & $60(57.1 \%)$ & $126(66.7 \%)$ & $0.002^{*}$ \\
\hline & Male & $18(21.4 \%)$ & $45(42.9 \%)$ & $63(33.3 \%)$ & \\
\hline \multirow[t]{2}{*}{ Institution } & Public & $29(34.5 \%)$ & $44(41.9 \%)$ & $73(38.6 \%)$ & 0.300 \\
\hline & Private & $55(65.5 \%)$ & $61(58.1 \%)$ & $116(61.4 \%)$ & \\
\hline \multirow[t]{5}{*}{ Qualification } & General practitioner & $47(55.9 \%)$ & $22(21 \%)$ & $69(36.5 \%)$ & $\leq 0.001^{*}$ \\
\hline & Specialist & $32(38.1 \%)$ & $59(56.2 \%)$ & $91(48.1 \%)$ & \\
\hline & Master's degree & $5(6 \%)$ & $16(15.2 \%)$ & $21(11.1 \%)$ & \\
\hline & $\mathrm{PhD}$ & $0(0)$ & $8(7.6 \%)$ & $8(4.2 \%)$ & \\
\hline & & $84(44.4 \%)$ & $105(55.6 \%)$ & $189(100 \%)$ & \\
\hline
\end{tabular}

Note. ${ }^{*} p$ values lower than 0.05 indicate statistically significant results.

TABle 2: Distribution of the number and percentages of responses to specific questions about oral cancer knowledge according to responders' seniority.

\begin{tabular}{|c|c|c|c|c|c|}
\hline \multirow{2}{*}{ Variables } & \multirow{2}{*}{ Categories } & \multicolumn{2}{|c|}{ Dental clinicians } & \multirow{2}{*}{ Total (\%) } & \multirow{2}{*}{$p$} \\
\hline & & Junior & Senior & & \\
\hline \multirow[t]{2}{*}{ Most common cancer } & Squamous cell carcinoma & $57(67.9 \%)$ & $68(64.8 \%)$ & $125(66.1 \%)$ & 0.655 \\
\hline & Other & $27(32.1 \%)$ & $37(35.2 \%)$ & $64(33.9 \%)$ & \\
\hline \multirow[t]{2}{*}{ Most frequent anatomical region } & Tongue & $50(59.5 \%)$ & $53(50.5 \%)$ & $103(54.5 \%)$ & 0.215 \\
\hline & Other & $34(40.5 \%)$ & $52(49.5 \%)$ & $86(45.5 \%)$ & \\
\hline \multirow[t]{2}{*}{ Most common aspect in initial cancer } & Painless ulcer & $72(85.7 \%)$ & $90(85.7 \%)$ & $162(85.7 \%)$ & 1.000 \\
\hline & Other & $12(14.3 \%)$ & $15(14.3 \%)$ & $27(14.3 \%)$ & \\
\hline \multirow[t]{2}{*}{ Most common age group } & More than 40 years old & $75(89.3 \%)$ & $92(87.6 \%)$ & $167(88.4 \%)$ & 0.723 \\
\hline & Other & $9(10.7 \%)$ & $13(12.4 \%)$ & $22(11.6 \%)$ & \\
\hline \multirow[t]{2}{*}{ Most characteristic regional lymph node metastasis } & $\begin{array}{c}\text { Hard, painless, } \\
\text { with or without mobility }\end{array}$ & $58(69 \%)$ & $73(69.5 \%)$ & $131(69.3 \%)$ & 0.944 \\
\hline & Other & $26(31 \%)$ & $32(30.5 \%)$ & $58(30.7 \%)$ & \\
\hline \multirow[t]{2}{*}{ Diagnostic status in Brazil } & Advanced & $64(76.2 \%)$ & $87(82.9 \%)$ & $151(79.9 \%)$ & 0.256 \\
\hline & Other & $20(23.8 \%)$ & $18(17.1 \%)$ & $38(20.1 \%)$ & \\
\hline \multirow[t]{3}{*}{ Most common condition associated with cancer } & Leukoplakia & $62(73.8 \%)$ & $79(75.2 \%)$ & $141(74.6 \%)$ & 0.823 \\
\hline & Other & $22(26.2 \%)$ & $26(24.8 \%)$ & $48(25.4 \%)$ & \\
\hline & & $84(44.4 \%)$ & $105(55.6 \%)$ & $189(100 \%)$ & \\
\hline
\end{tabular}

Note. $p$ values lower than 0.05 indicate statistically significant results; other $=$ one of the incorrect answers.

38.1\% declared themselves specialists, and 6\% had a Master's degree. On the other hand, among the senior dental clinicians, $56.2 \%$ reported being specialists, $21 \%$ were general dental practitioners, $15.2 \%$ had a Master's degree, and $7.6 \%$ held PhDs (Table 1). There was no statistical difference in the responses from both groups regarding the knowledge about the clinical characteristics of oral cancer (Table 2).

With regard to the risk factors of oral cancer development (Figure 1), there was a statistical difference between the two groups of professionals in the responses relating to "low consumption of fruit and vegetables," "poor fitting of dentures," "poor dental status," "poor oral hygiene," and "consumption of hot beverages and food" (Table 3).

Table 4 shows the response frequencies according to the factors related to attitudes toward oral cancer diagnosis and the perception about the topic according to the participants' seniority.

The multiple logistic regression analysis results indicated that the oral cancer knowledge of junior dental clinicians was 2.1 times higher in comparison to the senior dental clinicians' knowledge $(\mathrm{OR}=2.1 ; 1.1-3.995 \% \mathrm{CI} ; p=0.024)$ (Table 6). In addition, it was found that the professionals who had graduated from public institutions were 2.3 times 
TABLE 3: Distribution of the number and percentages of responses to specific questions addressing the knowledge about risk factors of oral cancer according to responders' seniority.

\begin{tabular}{|c|c|c|c|c|c|}
\hline \multirow{2}{*}{ Variables } & \multirow{2}{*}{ Categories } & \multicolumn{2}{|c|}{ Dental clinicians } & \multirow{2}{*}{ Total (\%) } & \multirow{2}{*}{$p$} \\
\hline & & Junior & Senior & & \\
\hline \multirow[t]{2}{*}{ Injected drug use } & Yes & $29(34.5 \%)$ & $30(28.6 \%)$ & $59(31.2 \%)$ & 0.380 \\
\hline & No & $55(65.5 \%)$ & $75(71.4 \%)$ & $130(68.8 \%)$ & \\
\hline \multirow[t]{2}{*}{ Had other types of cancer previously } & Yes & $70(83.3 \%)$ & $83(79 \%)$ & $153(81 \%)$ & 0.456 \\
\hline & No & $14(16.7 \%)$ & $22(21 \%)$ & $36(19 \%)$ & \\
\hline \multirow[t]{2}{*}{ Alcohol consumption } & Yes & $81(96.4 \%)$ & $105(100 \%)$ & $186(98.4 \%)$ & 0.051 \\
\hline & No & $3(3.6 \%)$ & $0(0)$ & $3(1.6 \%)$ & \\
\hline \multirow[t]{2}{*}{ Tobacco consumption } & Yes & $84(100 \%)$ & $105(100 \%)$ & $189(100 \%)$ & - \\
\hline & No & $0(0)$ & $0(0)$ & $0(0)$ & \\
\hline \multirow[t]{2}{*}{ Family history of cancer } & Yes & $80(95.2 \%)$ & $100(95.2 \%)$ & $180(95.2 \%)$ & 1.000 \\
\hline & No & $4(4.8 \%)$ & $5(4.8 \%)$ & $9(4.8 \%)$ & \\
\hline \multirow[t]{2}{*}{ Emotional stress } & Yes & $47(56 \%)$ & $71(67.6 \%)$ & $118(62.4 \%)$ & 0.100 \\
\hline & No & $37(44 \%)$ & $34(32.4 \%)$ & $71(37.6 \%)$ & \\
\hline \multirow[t]{2}{*}{ Lower consumption of fruit and vegetables } & Yes & $26(31 \%)$ & $50(47.6 \%)$ & $76(40.2 \%)$ & $0.020^{*}$ \\
\hline & No & $58(69 \%)$ & $55(52.4 \%)$ & $113(59.8 \%)$ & \\
\hline \multirow[t]{2}{*}{ Oral sex } & Yes & $43(51.2 \%)$ & $62(59 \%)$ & $105(55.6 \%)$ & 0.280 \\
\hline & No & $41(48.8 \%)$ & $43(41 \%)$ & $84(44.4 \%)$ & \\
\hline \multirow[t]{2}{*}{ Poorly fitting dentures } & Yes & $51(60.7 \%)$ & $98(93.3 \%)$ & $149(78.8 \%)$ & $\leq 0.001^{*}$ \\
\hline & No & $33(39.3 \%)$ & $7(6.7 \%)$ & $40(21.2 \%)$ & \\
\hline \multirow[t]{2}{*}{ Poor dental status } & Yes & $37(44 \%)$ & $80(76.2 \%)$ & 117 (61.9\%) & $\leq 0.001^{*}$ \\
\hline & No & $47(56 \%)$ & $25(23.8 \%)$ & $72(38.1 \%)$ & \\
\hline \multirow[t]{2}{*}{ Consumption of spicy food } & Yes & $20(23.8 \%)$ & $36(34.3 \%)$ & $56(29.6 \%)$ & 0.117 \\
\hline & No & $64(76.2 \%)$ & $69(65.7 \%)$ & $133(70.4 \%)$ & \\
\hline \multirow[t]{2}{*}{ Poor oral hygiene } & Yes & $34(40.5 \%)$ & $68(64.8 \%)$ & $102(54 \%)$ & $\leq 0.001^{*}$ \\
\hline & No & $50(59.5 \%)$ & $37(35.2 \%)$ & $87(46 \%)$ & \\
\hline \multirow[t]{2}{*}{ Direct infection } & Yes & $9(10.7 \%)$ & 19 (18.1\%) & $28(14.8 \%)$ & 0.156 \\
\hline & No & $75(89.3 \%)$ & $86(81.9 \%)$ & $161(85.2 \%)$ & \\
\hline \multirow[t]{2}{*}{ Sun exposure } & Yes & $76(90.5 \%)$ & $86(81.9 \%)$ & $162(85.7 \%)$ & 0.094 \\
\hline & No & $8(9.5 \%)$ & $19(18.1 \%)$ & $27(14.3 \%)$ & \\
\hline \multirow[t]{2}{*}{ Hot beverages and food } & Yes & $34(40.5 \%)$ & $78(74.3 \%)$ & $112(59.3 \%)$ & $\leq 0.001^{*}$ \\
\hline & No & $50(59.5 \%)$ & $27(25.7 \%)$ & 77 (40.7\%) & \\
\hline \multirow[t]{2}{*}{ Obesity } & Yes & $14(16.7 \%)$ & $17(16.2 \%)$ & $31(16.4 \%)$ & 0.930 \\
\hline & No & $70(83.3 \%)$ & $88(83.8 \%)$ & $158(83.6 \%)$ & \\
\hline \multirow[t]{3}{*}{ HPV infection } & Yes & $71(84.5 \%)$ & 97 (92.4\%) & $168(88.9 \%)$ & 0.088 \\
\hline & No & $13(15.5 \%)$ & $8(7.6 \%)$ & $21(11.1 \%)$ & \\
\hline & & $84(44.4 \%)$ & $105(55.6 \%)$ & $189(100 \%)$ & \\
\hline
\end{tabular}

Note. ${ }^{*} p$ values lower than 0.05 indicate statistically significant results.

more aware about oral cancer $(\mathrm{OR}=2.3 ; 1.2-4.3$ 95\% CI; $p=0.013)$. The participants who performed self-assessment and reported having satisfactory oral cancer knowledge (excellent or good) were 2.2 times more likely to have higher knowledge level $(\mathrm{OR}=2.2 ; 1.2-4.295 \% \mathrm{CI} ; p=0.013)$ in comparison to the participants who reported regular or poor knowledge level (Table 6).

\section{Discussion}

Studies assessing dentists' knowledge, opinions, and practices relating to the prevention and early detection of oral cancer have been carried out in several countries $[2,4,10,11$, $18,20-25,33-40]$. The use of Internet and e-mails to obtain information has increased in recent years [2, 20, 41]. No articles have been found in Brazil with regard to the assessment of the dentists' oral cancer knowledge level considering and comparing their practice seniority, that is, newly graduated professionals versus senior professionals.

In contrast to the response rate observed in this study, in a Japanese study [20], which used the same electronic platform and sent 131 questionnaires, the response rate was $62.6 \%$, represented by the 82 e-mails in response to the research. A Spanish study with 1,000 sent e-mails had 795 
TABLE 4: Distribution of the number and percentages of responses about attitudes toward diagnosis of cancer and perception about this issue according to responders' seniority.

\begin{tabular}{|c|c|c|c|c|c|}
\hline \multirow{2}{*}{ Variables } & \multirow{2}{*}{ Categories } & \multicolumn{2}{|c|}{ Dental clinicians } & \multirow{2}{*}{ Total $(\%)$} & \multirow{2}{*}{$p$} \\
\hline & & Junior & Senior & & \\
\hline \multirow[t]{2}{*}{ Self-assessment of knowledge } & Excellent/good & $46(54.8 \%)$ & $54(51.4 \%)$ & $100(52.9 \%)$ & 0.648 \\
\hline & Regular/poor & $38(45.2 \%)$ & $51(48.6 \%)$ & $89(47.1 \%)$ & \\
\hline \multirow[t]{2}{*}{ Performs cancer exam in the 1st appointment } & Yes & $66(78.6 \%)$ & $90(85.7 \%)$ & $156(82.5 \%)$ & 0.199 \\
\hline & No & $18(21.4 \%)$ & $15(14.3 \%)$ & $33(17.5 \%)$ & \\
\hline \multirow[t]{4}{*}{ Reason for not performing the exam } & Performed the exam & $67(79.8 \%)$ & $88(83.8 \%)$ & $155(82 \%)$ & 0.551 \\
\hline & I do not know how to do it & $8(9.5 \%)$ & $11(10.5 \%)$ & $19(10.1 \%)$ & \\
\hline & I do not think it is necessary & $6(7.1 \%)$ & $5(4.8 \%)$ & $11(5.8 \%)$ & \\
\hline & I do not receive fees & $3(3.6 \%)$ & $1(1 \%)$ & $4(2.1 \%)$ & \\
\hline \multirow[t]{5}{*}{ Referral of suspicious lesions } & Stomatology & $53(63.1 \%)$ & $73(69.5 \%)$ & $126(66.7 \%)$ & $0.007^{*}$ \\
\hline & Myself & $13(15.5 \%)$ & $19(18.1 \%)$ & $32(16.9 \%)$ & \\
\hline & Dental school & $15(17.9 \%)$ & $3(2.9 \%)$ & $18(9.5 \%)$ & \\
\hline & Specialized hospital & $2(2.4 \%)$ & $6(5.7 \%)$ & $8(4.2 \%)$ & \\
\hline & Physician & $1(1.2 \%)$ & $4(3.8 \%)$ & $5(2 \%)$ & \\
\hline \multirow[t]{3}{*}{ Confidence level } & High & $26(31 \%)$ & $40(38.1 \%)$ & $66(34.9 \%)$ & 0.407 \\
\hline & Low & $55(65.5 \%)$ & $59(56.2 \%)$ & $114(60.3 \%)$ & \\
\hline & I do not know & $3(3.6 \%)$ & $6(5.7 \%)$ & $9(4.8 \%)$ & \\
\hline \multirow[t]{3}{*}{ Training at the university } & Yes & $59(70.2 \%)$ & $46(43.8 \%)$ & $105(55.6 \%)$ & $\leq 0.001^{*}$ \\
\hline & No & $25(29.8 \%)$ & $55(52.4 \%)$ & $80(42.3 \%)$ & \\
\hline & I do not know & $0(0)$ & $4(3.8 \%)$ & $4(2.1 \%)$ & \\
\hline \multirow[t]{6}{*}{ Attended a course on oral cancer } & Last year & $17(20.2 \%)$ & $13(12.4 \%)$ & $30(15.9 \%)$ & $0.006^{*}$ \\
\hline & Two years ago & $24(28.6 \%)$ & $20(19 \%)$ & $44(23.3 \%)$ & \\
\hline & More than two years ago & $19(22.6 \%)$ & $52(49.5 \%)$ & $71(37.6 \%)$ & \\
\hline & Never & $14(16.9 \%)$ & $12(11.4 \%)$ & $26(13.8 \%)$ & \\
\hline & I do not remember & $10(11.9 \%)$ & $8(7.6 \%)$ & $18(9.5 \%)$ & \\
\hline & & $84(44.4 \%)$ & $105(55.6 \%)$ & $189(100 \%)$ & \\
\hline
\end{tabular}

Note. ${ }^{*} p$ values lower than 0.05 indicate statistically significant results.

acknowledged as received and $340(42.7 \%)$ responded questionnaires [2]. In contrast, another Brazilian study [27] sent 5,000 questionnaires via e-mail and the response rate was $1.4 \%$, suggesting that the Brazilian professional population may be less partaking in scientific research, especially with respect to the elected method of data collection.

Therefore, it is natural to envision that Brazilian dentists have little interest in the subject. However, one possible explanation for the low response rate in the present study could be the excessive circulating advertising or spam and the ease with which they can be ignored or discarded [2]. However, the authors agree with López-Jornet et al. [2] when they say that this sort of communication is faster and easier to manage, in addition to being less costly. Therefore, new efforts and resources should be made for e-mails to be taken into consideration in future research so that important contents do not go unnoticed.

Nevertheless, despite these limitations of the low response rate, the number of participants (477) represents an expressive sample in comparison to the ones found in literature $[2,4,10$, $18,20,22-24,27-29,36,42]$. Therefore, the present study provides significant information about the knowledge of dentists in São Paulo that may contribute to new projects.
According to the dentists' obtained knowledge level grades, there was a statistical difference between newly graduated clinicians and senior dental clinicians (Table 1). Among junior dental clinicians, 19\% obtained grade A (excellent) in comparison to $6.7 \%$ of senior dental clinicians. The results of the logistic regression analysis indicated that the knowledge level of junior dental clinicians was 2.1 times higher $(\mathrm{OR}=2.1 ; 1.1-3.995 \% \mathrm{CI} ; p=0.024)$ (Table 6). This result is similar to that of other studies $[4,25]$.

Although there was a significant difference between the two groups, the data analysis allowed to observe that there are many concepts that are still not well-defined amongst professionals of both groups, showing that there is much to be discussed on means to stimulate oral cancer knowledge building.

In the question about the anatomical region of higher oral cancer prevalence (Figure 1), $45.5 \%$ of participants did not know the answer (Table 2). Rocha-Buelvas et al. [24] revealed that only a few professionals knew the most frequent locations of oral malignance. This is disturbing because if the professionals do not have the adequate knowledge about the most frequent locations of oral cancer development, then the injury may go unnoticed during 
TABLE 5: Distribution of the number and percentages of responses relating to the dentists' general characteristics according to their selfassessment of oral cancer knowledge.

\begin{tabular}{|c|c|c|c|c|c|}
\hline \multirow[t]{2}{*}{ Variables } & \multirow[t]{2}{*}{ Categories } & \multicolumn{2}{|c|}{$\begin{array}{l}\text { Self-assessment of the level of } \\
\text { knowledge about oral cancer }\end{array}$} & \multirow[t]{2}{*}{ Total $(\%)$} & \multirow[t]{2}{*}{$p$} \\
\hline & & Satisfactory & Unsatisfactory & & \\
\hline \multirow[t]{2}{*}{ Institution } & Public & $43(43 \%)$ & $30(33.7 \%)$ & $73(38.6 \%)$ & 0.190 \\
\hline & Private & $57(57 \%)$ & $59(66.3 \%)$ & $116(61.4 \%)$ & \\
\hline \multirow[t]{2}{*}{ Time of experience } & Junior dental clinicians & $46(46 \%)$ & $38(42.7 \%)$ & $84(44.4 \%)$ & 0.648 \\
\hline & Senior dental clinicians & $54(54 \%)$ & $51(57.3 \%)$ & $105(55.6 \%)$ & \\
\hline \multirow[t]{2}{*}{ Qualification } & General practitioner & $35(35 \%)$ & $34(38.2 \%)$ & $69(36.5 \%)$ & 0.648 \\
\hline & Graduated $^{1}$ & $65(65 \%)$ & $55(61.8 \%)$ & $120(63.5 \%)$ & \\
\hline \multirow[t]{2}{*}{ Training at the university } & Yes & $66(66 \%)$ & $39(43.8 \%)$ & $105(55.6 \%)$ & $0.002^{*}$ \\
\hline & No/I do not know & $34(34 \%)$ & $50(56.2 \%)$ & $84(44.4 \%)$ & \\
\hline \multirow[t]{2}{*}{ Attended a course on oral cancer } & Two years ago & $53(53 \%)$ & $21(23.6 \%)$ & $74(39.2 \%)$ & $\leq 0.001^{*}$ \\
\hline & More than two years ago/never & $47(47 \%)$ & $68(76.4 \%)$ & $115(60.8 \%)$ & \\
\hline \multirow[t]{3}{*}{ Grades obtained } & A-B (excellent/good) & $67(67 \%)$ & $39(43.8 \%)$ & $106(56.1 \%)$ & $\leq 0.001$ * \\
\hline & C-D (regular/poor) & $33(33 \%)$ & $50(56.2 \%)$ & $83(43.9 \%)$ & \\
\hline & & $100(52.9 \%)$ & $89(47.1 \%)$ & $189(100 \%)$ & \\
\hline
\end{tabular}

Note. ${ }^{*} p$ values lower than 0.05 indicate statistically significant results. ${ }^{1}$ The "Graduated" category refers to the participants that reported having specialization, Master's degree, and/or $\mathrm{PhD}$.

TABLE 6: Association of the general characteristics and clinical practice of the dentists relating to the level of knowledge about oral cancer according to attributed grades $(\mathrm{A}=$ excellent; $\mathrm{B}=$ good $)$.

\begin{tabular}{|c|c|c|c|c|}
\hline \multirow{2}{*}{ Characteristics } & \multirow{2}{*}{ Categories } & \multicolumn{3}{|c|}{ Grades obtained $(\mathrm{A}=$ excellent; $\mathrm{B}=$ good $)$} \\
\hline & & Number (\%) & OR $(95 \% \mathrm{CI})$ & $p$ \\
\hline \multirow[t]{2}{*}{ Self-assessment of knowledge } & Satisfactory & $100(52.9 \%)$ & $2.2(1.2-4.2)$ & $0.013^{*}$ \\
\hline & Unsatisfactory & $89(47.1 \%)$ & & \\
\hline \multirow[t]{2}{*}{ Time of experience } & Junior dental clinicians & $84(44.4 \%)$ & $2.1(1.1-3.9)$ & $0.024^{*}$ \\
\hline & Senior dental clinicians & $105(55.6 \%)$ & & \\
\hline \multirow[t]{2}{*}{ Graduation institution } & Public & $73(38.6 \%)$ & $2.3(1.2-4.3)$ & $0.013^{*}$ \\
\hline & Private & $116(61.4 \%)$ & & \\
\hline \multirow[t]{2}{*}{ Attended a course on oral cancer } & Two years ago & $74(39.2 \%)$ & $1.5(0.8-2.9)$ & 0.234 \\
\hline & More than two years ago or never & $115(60.8 \%)$ & & \\
\hline
\end{tabular}

Note. ${ }^{*} p$ values lower than 0.05 indicate statistically significant results. The time when the responder attended a course on oral cancer was an adjustment variable for the multiple logistic regression analysis.

a routine examination and, thus, the disease diagnosis may be delayed or ignored.

Our study revealed that one-third of the respondents do not know about regional metastases (Table 2), which coincides with a study conducted in New York, USA [21]; other studies found that less than $40 \%$ of dentists have reported that they palpated the patients' lymph nodes during the complete examination of oral cavities [11, 43]. These data highlight the need to improve the professionals' level of knowledge about clinical characteristics and cancer screening, giving that lymph node palpation often aids in the diagnosis of the disease during its asymptomatic stage.

The questions regarding the risk factors of the disease (tobacco, alcohol, and HPV) (Figure 1) were properly answered by the groups of professionals (Table 3), in opposition to a Japanese study [20], in which alcohol and $\mathrm{HPV}$ were poorly identified as risk factors for oral cancer. It is possible that the results of these studies are due to massive campaigns about the dangers of cigarettes and alcohol.

An interesting aspect was the controversy about the trauma of poor denture fitting (Figure 1), since $60.7 \%$ of junior clinicians and $93.3 \%$ of senior clinicians reported that it was a risk factor (Table 3), demonstrating that, despite the statistical difference, more than $60 \%$ of the professionals took this controversial issue into consideration. Although from the scientific perspective, the injuries caused by poor denture fitting do not cause cancer, these chronic injuries alter the oral environment and mask the symptoms, and initial lesions may not be properly diagnosed. Therefore, the professionals should eliminate these traumatic factors in the maintenance of oral health.

In the current study, 54\% of respondents answered that poor oral hygiene (Figure 1) is a risk factor for oral cancer (Table 3). However, the role of poor oral hygiene is controversial, and this study corroborates with the observations 
from Oji and Chukwuneke [44], considering that only a major prospective study would provide appropriate information to scientifically clarify its impact in oral cancer genesis.

The low consumption of fruit and vegetables (Figure 1) was considered as a risk factor for oral cancer by $40.2 \%$ of professionals (Table 3). It is believed that eating fruit and vegetables may reduce the risk of cancer, including oral cancer, because they play an important part as a protective factor. Shivappa et al. [45] suggested a positive interaction between a proinflammatory diet with alcohol consumption and smoking in association with oral cancer. However, Dholam and Chouksey [46] found that a diet as a risk factor for oral cancer was not statistically significant. Moreover, this study agrees with Scully's [5] research that randomized clinical trials are needed to explore the effectiveness of dietary supplementation as chemoprevention to reduce the risk of oral cancer.

It is worth mentioning the importance appointed by the professionals regarding emotional stress (Figure 1). This issue was reported as a risk factor for oral cancer by $62.4 \%$ of dentists (Table 3 ). A recent study found an increased risk of oral cancer in patients who had suffered emotional stress. However, according to Dholam and Chouksey [46], emotional stress is a modern life symptom, and it may be responsible for delays in diagnosis due to work and familyrelated commitments, which probably generate patients' negligence toward their symptoms, but emotional stress would not be the core cause of oral cancer. Prospective studies with oral cancer patients would be necessary, excluding those who have scientifically proven risk factors, such as tobacco and alcohol consumption, and/or genetic factors, to show whether emotional stress alone could cause the disease.

The assessment of the variable "oral sex" (Figure 1) indicated a considerable number of positive responses, being a risk factor for $55.6 \%$ of professionals (Table 3). Nevertheless, these results may be a confounding factor because they probably associate oral sex with the possibility of HPV infection, which is strongly related to oral cancer $[3,7,47]$. Therefore, it is essential to provide patients with information about HPV and regarding the importance of preventive methods during sexual intercourse, in addition to the possibility of vaccination as a method to prevent virus infection.

Considering the attitudes for the diagnosis of suspected lesions (Figure 1), 17.9\% of junior dental clinicians reported that they usually referred these cases to dental schools, compared to $2.4 \%$ of senior dental clinicians (Table 4 ). These results may be due to the fact that recent graduates feel more familiar with those institutions, possibly due to their recent undergraduation.

When asked about oral cancer screening training during the undergraduation (Figure 1), 70.2\% of the junior clinicians reported having received training, compared to $43.8 \%$ of senior clinicians (Table 4 ). This means that almost $30 \%$ of the professionals were not properly trained, demonstrating that much needs to be improved in that aspect, considering the importance and seriousness of the matter. A study conducted in Spain [2] found that dentists, who were trained on oral cancer during their undergraduation, were more likely to agree that they had updated knowledge. This finding corroborates with the ones of the present study, since $66 \%$ of the participants that "rated themselves with satisfactory knowledge level" (excellent or good) reported that they had been trained for the examination of oral cancer during their undergraduation studies $(p=0.002)$ (Table 5 ). In addition, logistic regression analysis indicated that they were 2.2 times more likely to have greater knowledge about the disease $(\mathrm{OR}=2.2 ; 1.2-4.295 \% \mathrm{CI} ; p=0.013$ ) (Table 6).

The logistic regression analysis indicated that dentists who graduated from public institutions had 2.3 times more knowledge about oral cancer in comparison to private institutions' graduates $(\mathrm{OR}=2.3 ; 1.2-4.395 \% \mathrm{CI} ; p=0.013$ ) (Table 6), demonstrating that specific studies on the analysis of the curriculum of public and private universities may be object of further research.

Considering participation in "continuing education courses on oral cancer" (Figure 1), 39.2\% of the professionals had attended a course on oral cancer in the previous year or in the last two years (Table 4). This result is disturbing since the knowledge acquired during undergraduation tends to weaken with the absence of further knowledge support or updates [23]. Also, in the present study, 53\% of the participants that reported satisfactory knowledge level (excellent or good) had attended a course on oral cancer in the last two years $(p \leq 0.001)$ (Table 5), coinciding with the study carried out by Hertrampf et al. [36], which found that the perceptions and practice relating to early detection of oral cancer had improved, particularly in the group of dentists that had attended further educational courses, emphasizing that these programs improved dental professionals' competence, findings in agreement with other studies [10, 23-25]. In Spain, the professionals who had benefited from continuing education courses were 3.5 times more likely to perform biopsies in suspicious lesions and twice as likely to give advice about alcohol consumption to patients [48], demonstrating the positive effect of further studies and professional updates.

Therefore, it is necessary that the professionals have greater interest in continuing education courses so that their knowledge and skills may be updated, contributing to the oral cancer prevention and minimizing practical failures regarding cancer screening, providing, when necessary, early disease detection.

The results of the present study demonstrated that although the junior dental clinicians had a knowledge level 2.1 times higher compared to senior dental clinicians (Table 6), there is still lack of knowledge about some topics related to risk factors and clinical characteristics of the disease.

Probably, as these results may be explained by the fact that the information obtained by newly graduated clinicians was more updated, or due to the lack of practice in the area, more experienced dentists were not interested in the subject. Further studies conducted with a larger number of professionals are required to confirm the results of this study.

\section{Conclusion}

Within the limitations of the study due to the low percentage of responses, we can conclude that, among the studied population, the newly graduated clinicians had a 2.1 times 
higher knowledge level in comparison to dentists who had more than 30 years of practice experience. However, when several factors regarding the knowledge of the risk factors and diagnostic procedures were individually assessed, the results indicated high rates of incorrect answers, demonstrating that there is room for further studies in the area and for oral cancer information activities. Therefore, oral cancer aspects must be emphasized so that more people, clinicians, and patients become interested in the topic. This goal may be achieved through clarification campaigns, dental school's program improvement, and the encouragement of professionals in attending continuing education courses for better qualification. New studies must be performed to compare our results.

\section{Conflicts of Interest}

The authors have no financial interest in companies whose materials were included in the present study, nor any further interest that may present conflicts associated with this publication.

\section{References}

[1] J. Seoane, P. Alvarez-Novoa, I. Gomez et al., "Early oral cancer diagnosis: the Aarhus statement perspective. A systematic review and meta-analysis," Head \& Neck, vol. 38, no. 1, pp. E2182-E2189, 2016.

[2] P. López-Jornet, F. Camacho-Alonso, and F. Molina-Miñano, "Knowledge and attitudes about oral cancer among dentists in Spain," Journal of Evaluation in Clinical Practice, vol. 16, no. 1, pp. 129-133, 2010.

[3] Brasil. Ministério da Saúde. Instituto Nacional de Câncer, "Incidência de câncer no Brasil: estimativa 2016. Rio de janeiro: INCA.estimativa-2016-v11.pdf," January 2017. http://www. inca.gov.br/estimativa/2016/estimativa-2016-v11.pdf.

[4] N. A. Alaizari and S. A. Al-Maweri, "Oral cancer: knowledge, practices and opinions of dentists in Yemen," Asian Pacific Journal of Cancer Prevention, vol. 15, no. 14, pp. 5627-5631, 2014.

[5] C. Scully, "Oral cancer aetiopathogenesis; past, present and future aspects," Medicina Oral Patología Oral y Cirugia Bucal, vol. 16, no. 3, pp. e306-e311, 2011.

[6] J.-M. Seoane-Romero, I. Vázquez-Mahía, J. Seoane, P. VarelaCentelles, I. Tomás, and J.-L. López-Cedrún, "Factors related to late stage diagnosis of oral squamous cell carcinoma," Medicina Oral Patología Oral y Cirugia Bucal, vol. 17, no. 1, pp. e35-e40, 2012.

[7] C. Carreras-Torras and C. Gay-Escoda, "Techniques for early diagnosis of oral squamous cell carcinoma: systematic review," Medicina Oral Patología Oral y Cirugia Bucal, vol. 20, no. 3, pp. e305-e315, 2015.

[8] S. N. Andrade, L. V. Muniz, J. M. A. Soares, A. L. F. Chaves, and R. I. M. A. Ribeiro, "Câncer de boca: avaliação do conhecimento e conduta dos dentistas na atenção primária à saúde," Revistas, vol. 71, no. 1, pp. 42-47, 2014.

[9] C. L. Tax, S. K. Haslam, M. Brillant, H. J. Doucette, J. E. Cameron, and S. E. Wade, "Oral cancer screening: knowledge is not enough," International Journal of Dental Hygiene, vol. 15, no. 3, pp. 179-186, 2015.

[10] J. Seoane-Lestón, J. Velo-Noya, S. Warnakulasuriya et al., "Knowledge of oral cancer and preventive attitudes of Spanish dentists. Primary effects of a pilot educational intervention," Medicina Oral Patología Oral y Cirugia Bucal, vol. 15, no. 3, pp. e422-e426, 2010.

[11] K. V. Vijay Kumar and V. Suresan, "Knowledge, attitude and screening practices of general dentists concerning oral cancer in Bangalore city," Indian Journal of Cancer, vol. 49, no. 1, pp. 33-38, 2012.

[12] A. L. N. Francisco, M. V. Furlan, P. M. Peresi et al., "Head and neck mucosal melanoma: clinicopathological analysis of 51 cases treated in a single cancer centre and review of the literature," International Journal of Oral and Maxillofacial Surgery, vol. 45, no. 2, pp. 135-140, 2016.

[13] P. Güneri and J. B. Epstein, "Late stage diagnosis of oral cancer: components and possible solutions," Oral Oncology, vol. 50, no. 12, pp. 1131-1136, 2014.

[14] F. Esmaelbeigi, M. Hadji, I. Harirchi, R. Omranipour, M. vand Rajabpour, and K. Zendehdel, "Factors affecting professional delay in diagnosis and treatment of oral cancer in Iran," Archives of Iranian Medicine, vol. 17, no. 4, pp. 253-257, 2014.

[15] F. B. Sousa, M. R. de Freitas e Silva, C. P. Fernandes, P. G. de Barros Silva, and A. P. N. N. Alves, "Oral cancer from a health promotion perspective: experience of a diagnosis network in Ceará," Brazilian Oral Research, vol. 28, no. 1, pp. 1-8, 2014.

[16] E. Traebert and J. Traebert, "Oral cancer in Brazil: dentists' lack of technical knowledge," Brazilian Oral Research, vol. 29, no. 1, pp. 1-2, 2015.

[17] Brasil. Conselho Federal de Odontologia, "Estatísticas. Quadro_ estatistico_faculdade.pdf," November 2016, http://cfo.org.br/wpcontent/uploads/2009/10/quadro_estatistico_faculdade.pdf.

[18] G. Colella, G. M. Gaeta, A. Moscariello, and I. F. Angelillo, "Oral cancer and dentists: knowledge, attitudes, and practices in Italy," Oral Oncology, vol. 44, no. 4, pp. 393-399, 2008.

[19] L. L. Dib, R. S. Souza de, and N. Tortamano, "Avaliação do conhecimento sobre câncer bucal entre alunos de odontologia, em diferentes unidades da Universidade Paulista," Journal of Health Science Institute, vol. 23, no. 4, pp. 287-295, 2005.

[20] S. Haresaku, M. Makino, S. Sugiyama, T. Naito, and R. J. Mariño, "Comparison of practices, knowledge, confidence, and attitude toward oral cancer among oral health professionals between Japan and Australia," Journal of Cancer Education, 2016.

[21] S. Gajendra, G. D. Cruz, and J. V. Kumar, "Oral cancer prevention and early detection: knowledge, practices, and opinions of oral health care providers in New York State," Journal of Cancer Education, vol. 21, no. 3, pp. 157-162, 2006.

[22] M. Greenwood and R. J. Lowry, "Primary care clinicians' knowledge of oral cancer: a study of dentists and doctors in the North East of England," British Dental Journal, vol. 191, no. 9, pp. 510-512, 2001.

[23] M. Pentenero, A. Chiecchio, and S. Gandolfo, "Impact of academic and continuing education on oral cancer knowledge, attitude and practice among dentists in north-western Italy," Journal of Cancer Education, vol. 29, no. 1, pp. 151-157, 2014.

[24] A. Rocha-Buelvas, C. Hidalgo-Patiño, G. Collela, and I. Angelillo, "Oral cancer and dentists: knowledge, attitudes and practices in a South Colombian context," Acta Odontológica Latinoamericana, vol. 25, no. 2, pp. 155-162, 2012.

[25] J. B. Clovis, A. M. Horowitz, and D. H. Poel, "Oral and pharyngeal cancer: knowledge and opinions of dentists in British Columbia and Nova Scotia," Journal of Canadian Dental Association, vol. 68, no. 7, pp. 415-420, 2002.

[26] T. M. N. de Morais, Câncer de Boca: Avaliação do Conhecimento dos Cirurgióes Dentistas Quanto Aos Fatores de Risco e Procedimentos de Diagnóstico, M.S. thesis, São Paulo: 
Universidade de São Paulo, Faculdade de Odontologia, Dental Graduate Program, São Paulo, Brazil, 2003.

[27] A. C. B. S. Cimardi and A. P. S. Fernandes, "Câncer bucal: a prática e a realidade clínica dos cirurgiões-dentistas de Santa Catarina," RFO UPF, vol. 14, no. 2, pp. 99-104, 2009.

[28] M. M. L. Falcão, T. D. B. Alves, V. S. Freitas, and T. C. B. Coelho, "Conhecimento dos cirurgiões-dentistas em relação ao câncer bucal,” RGO, vol. 58, no. 1, pp. 27-33, 2010.

[29] M. L. Alvarenga, M. G. Couto, A. Ribeiro, R. C. M. Milagres, M. R. Messora, and L. T. Kawata, "Avaliação do conhecimento dos cirurgiões-dentistas quanto ao câncer bucal," RFO UPF, vol. 17, no. 1, pp. 31-35, 2012.

[30] S. T. Ildstad, D. J. Tollerud, M. E. Bigelow, and J. P. Remensnyder, "A multivariate analysis of determinants of survival for patients with squamous cell carcinoma of the head and neck," Annals of Surgery, vol. 209, no. 2, pp. 237-241, 1989.

[31] A. Mashberg and A. M. Samit, "Early detection, diagnosis, and management of oral and oropharyngeal cancer," Cancer Journal for Clinicians, vol. 39, no. 2, pp. 67-88, 1989.

[32] L. L. Dib, D. S. Pinto, L. C. Sanvitto, H. Contesini, V. Lombardo, and E. Franco, "Determinantes de sobrevida em câncer de boca: fatores sócio-demográficos e anatômicos," Revista Brasileira de Cirurgia de Cabeça e Pescoço, vol. 14, no. 1, pp. 1-9, 1990.

[33] C. Maybury, A. M. Horowitz, and H. S. Goodman, "Outcomes of oral cancer early detection and prevention statewide model in Maryland," Journal of Public Health Dentistry, vol. 72, no. 1, pp. S34-S38, 2012.

[34] E. Applebaum, T. N. Ruhlen, F. R. Kronenberg, C. Hayes, and E. S. Peters, "Oral cancer knowledge, attitudes and practices: a survey of dentists and primary care physicians in Massachusetts," Journal of the American Dental Association, vol. 140, no. 4, pp. 461-467, 2009.

[35] A. M. Horowitz, P. Siriphant, A. Sheikh, and W. L. Child, "Perspectives of Maryland dentists on oral cancer," Journal of the American Dental Association, vol. 132, no. 1, pp. 65-72, 2001.

[36] K. Hertrampf, H.-J. Wenz, M. Koller, S. Grund, and J. Wiltfang, "Early detection of oral cancer: dentists' opinions and practices before and after educational interventions in Northern-Germany," Journal of Cranio-Maxillofacial Surgery, vol. 41, no. 8, pp. 201-207, 2013.

[37] L. L. Patton, J. R. Elter, J. H. Southerland, and R. P. Strauss, "Knowledge of oral cancer risk factors and diagnostic concepts among North Carolina dentists. Implications for diagnosis and referral," Journal of the American Dental Association, vol. 136, no. 5, pp. 602-610, 2005.

[38] O. Kujan, A. J. Duxbury, A. M. Glenny, N. S. Thakker, and P. Sloan, "Opinions and attitudes of the UK's GDPs and specialists in oral surgery, oral medicine and surgical dentistry on oral cancer screening," Oral Diseases, vol. 12, no. 2, pp. 194-199, 2006.

[39] J. A. Yellowitz, A. M. Horowitz, T. F. Drury, and H. S. Goodman, "Survey of U.S. dentists' knowledge and opinions about oral pharyngeal cancer," Journal of the American Dental Association, vol. 131, no. 5, pp. 653-661, 2000.

[40] A. Y. Alami, R. F. El Sabbagh, and A. Hamdan, "Knowledge of oral cancer among recently graduated medical and dental professionals in Amman, Jordan," Journal of Dental Education, vol. 77, no. 10, pp. 1356-1364, 2013.

[41] E. Daley, V. Dodd, R. DeBate et al., "Prevention of HPVrelated oral cancer: assessing dentists' readiness," Public Health, vol. 128, no. 3, pp. 231-238, 2014.

[42] J. C. Leão, P. Góes, C. B. Sobrinho, and S. Porter, "Knowledge and clinical expertise regarding oral cancer among Brazilian dentists," International Journal of Oral and Maxillofacial Surgery, vol. 34, no. 4, pp. 436-439, 2005.

[43] Ö. Kebabcioğlu and F. N. Pekiner, "Assessing oral cancer awareness among dentists," Journal of Cancer Education, 2017.

[44] C. Oji and F. Chukwuneke, "Poor oral hygiene may be the sole cause of oral cancer," Journal of Maxillofacial and Oral Surgery, vol. 11, no. 4, pp. 379-383, 2012.

[45] N. Shivappa, J. R. Hébert, V. Rosato, W. Garavello, D. Serraino, and C. La Vecchia, "Inflammatory potential of diet and risk of oral and pharyngeal cancer in a large casecontrol study from Italy," International Journal of Cancer, vol. 141, no. 3, pp. 471-479, 2017.

[46] K. P. Dholam and G. C. Chouksey, "Squamous cell carcinoma of the oral cavity and oropharynx in patients aged $18-45$ years: a case-control study to evaluate the risk factors with emphasis on stress, diet, oral hygiene, and family history," Indian Journal of Cancer, vol. 53, no. 2, pp. 244-251, 2016.

[47] S. De Santis, M. C. Spinosi, J. Cambi, C. Bengala, and S. Boccuzzi, "Oropharyngeal squamous cell carcinoma and HPV. Systematic review on overall management," Journal of Stomatology, Oral and Maxillofacial Surgery, vol. 118, no. 2, pp. 103-108, 2017.

[48] J. Seoane, P. Varela-Centelles, I. Tomás, J. Seoane-Romero, P. Diz, and B. Takkouche, "Continuing education in oral cancer prevention for dentists in Spain," Journal of Dental Education, vol. 76, no. 9, pp. 1234-1240, 2012. 


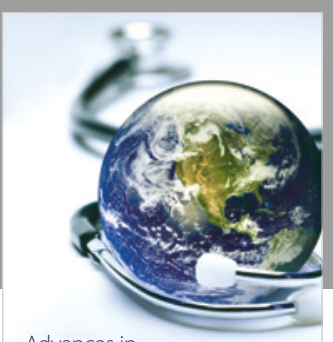

Advances in
Public Health

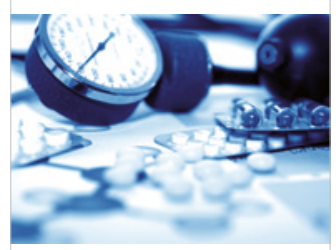

Case Reports in

Medicine

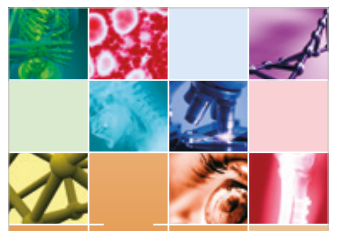

niernational Journal of

Biomaterials
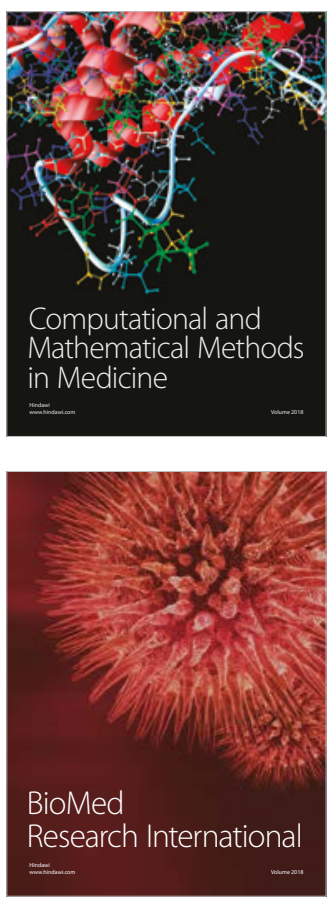

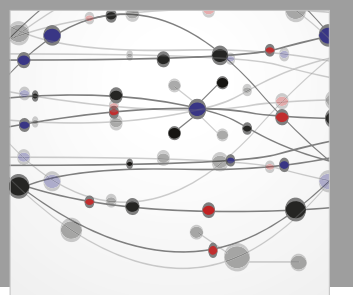

The Scientific World Journal Dentistry

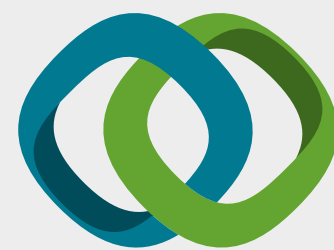

Hindawi

Submit your manuscripts at

www.hindawi.com
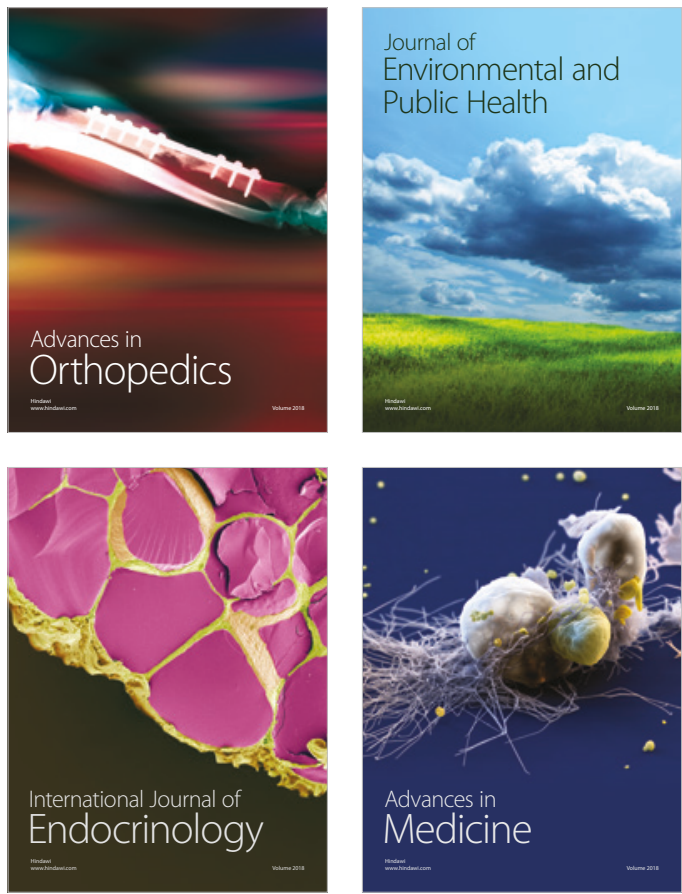
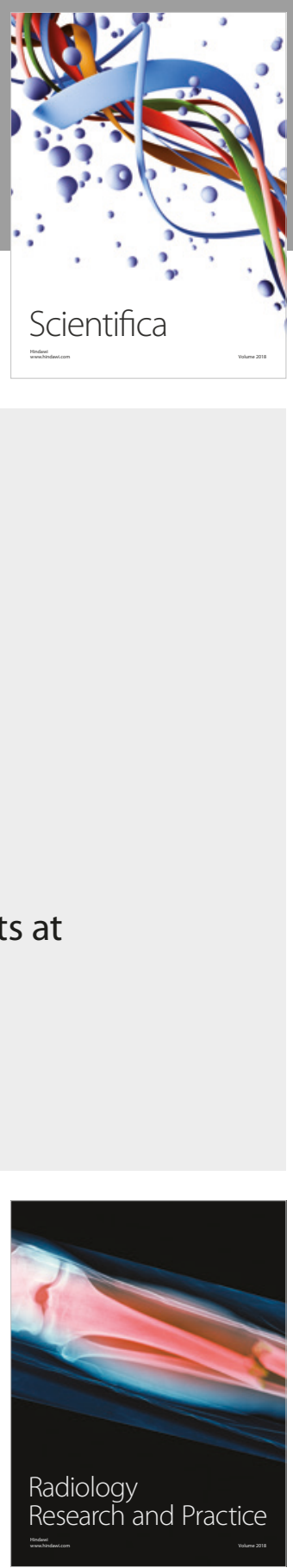

Scientifica

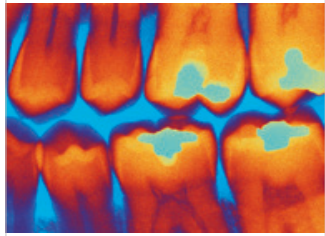

Case Reports in

Dentistry
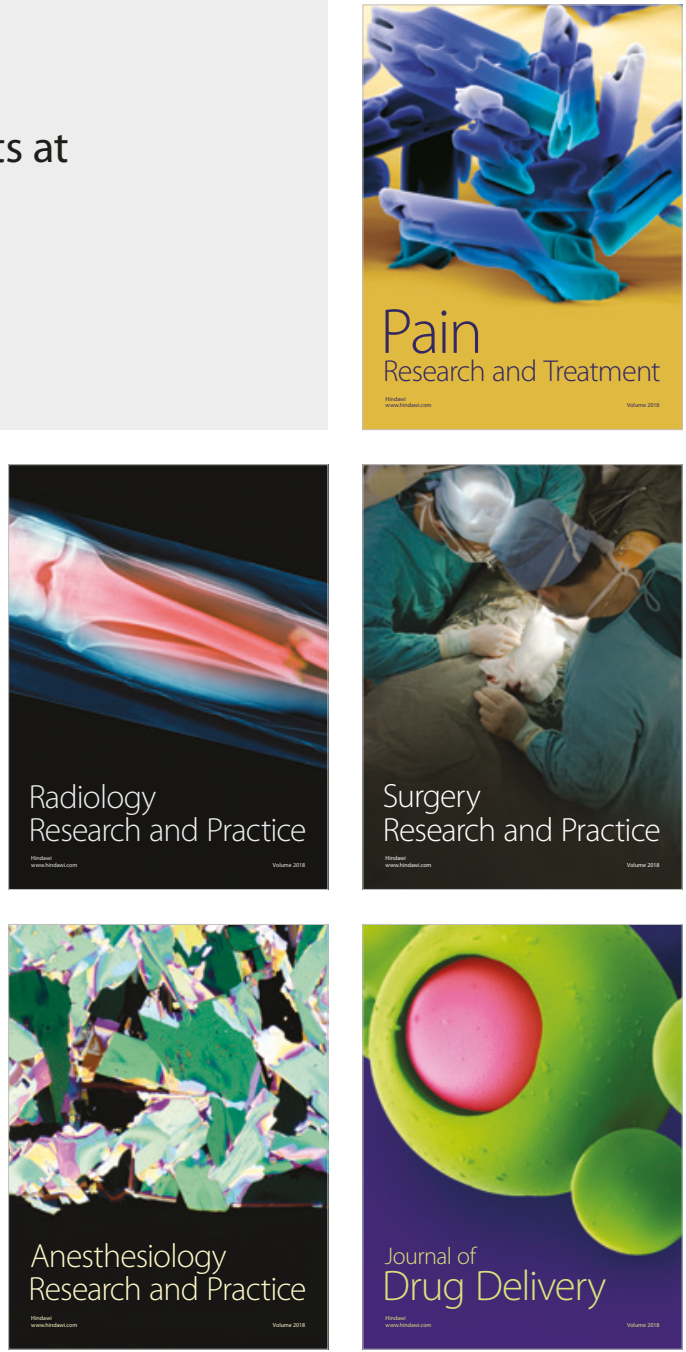